\title{
Evaluation of the impact resistance of various composite sandwich beams by vibration tests
}

\author{
Amir Shahdin ${ }^{\mathrm{a}}$, Joseph Morlier ${ }^{\mathrm{a}, *}$, Laurent Mezeix ${ }^{\mathrm{b}}$, Christophe Bouvet $^{\mathrm{a}}$ and Yves Gourinat ${ }^{\mathrm{a}}$ \\ ${ }^{a}$ Université de Toulouse, ISAE/DMSM, Campus Supaero, 10 av. Edouard Belin BP 54032, 31055 Toulouse, France \\ ${ }^{\mathrm{b}}$ Université de Toulouse, INPT-ENSIACET/CIRIMAT, 118 route de Narbonne, 31077 Toulouse, France
}

Received 18 September 2009

Revised 5 May 2010

\begin{abstract}
Impact resistance of different types of composite sandwich beams is evaluated by studying vibration response changes (natural frequency and damping ratio). This experimental works will help aerospace structural engineer in assess structural integrity using classification of impact resistance of various composite sandwich beams (entangled carbon and glass fibers, honeycomb and foam cores). Low velocity impacts are done below the barely visible impact damage (BVID) limit in order to detect damage by vibration testing that is hardly visible on the surface. Experimental tests are done using both burst random and sine dwell testing in order to have a better confidence level on the extracted modal parameters. Results show that the entangled sandwich beams have a better resistance against impact as compared to classical core materials.
\end{abstract}

Keywords: Structural integrity assessment, composite sandwich beams, vibration testing, impact resistance

\section{Introduction}

The aim of composite sandwich structures is to increase the stiffness and specific strength and to reduce the weight so it is advantageous to employ them in aerospace applications where the challenge is to produce structures lighter and lighter. However damage in these structures may negate many of the benefits of sandwich construction. Impact can induce various types of damage in the structure. The facesheets can be damaged through delamination and fibre breakage; the facesheet and core interface region can be debonded and the core can be damaged through crushing and shear failure mechanisms. Safe and functional effectiveness of stressed sandwich structures can often depend on the retention of integrity of each of the different materials used in its manufacture. Therefore lightweight sandwich materials used in next generation of more advanced aircraft, marine craft, road and rail vehicles must possess the capability to absorb high impacts. For aeronautical structures, a field where this problem has been extensively studied, the components have to undergo low energy impacts caused by dropped tools, mishandling during assembly and maintenance, and in-service impacts by foreign objects such as stones or birds. In these low energy impacts normally, a small indentation is seen on the impact surface. This level of damage is often referred to as barely visible impact damage (BVID).

Although not visually apparent, low energy impact damage is found to be quite detrimental to the load bearing capacities of sandwich structures, underscoring the need for reliable damage detection techniques for composite sandwich structures. In recent years, vibration based damage detection has been rapidly expanding and has shown to be a feasible approach for detecting and locating damage. A detailed and comprehensive overview on the vibration based damage detection methods has been presented in references [1-5]. The basic principle of vibration based damage detection can be explained as follows. Any structure can be considered as a dynamic system with stiffness,

${ }^{*}$ Corresponding author. Tel.: +3356133 81 31; Fax: +33 5613383 30; E-mail: joseph.morlier@isae.fr. 
mass and damping. Once some damages emerge in the structures, the structural parameters will change, and the frequency response functions and modal parameters of the structural system will also change. This change of modal parameters can be taken as the signal of initial damage occurrence in the structural system. Shift in natural frequency is the most common parameter used in the identification of damage. A large variety of works can be found in the scientific literature related to the study of structural damage by changes in natural frequencies [6-10]. However, in structures made of composite materials there seems to be a tendency to use damping as a damage indicator tool, as it tends to be more sensitive to damage than the stiffness variations, mainly when delamination is concerned. Therefore damping has been proposed in scientific literature as a more sensitive and attractive damage indicator as compared to natural frequencies [11-15].

There has been considerable research on the impact performance and damage development in carbon fiber composite materials and sandwich composite materials; see for example references [16-19]. A comprehensive review of low-velocity impact responses of composite materials is presented by Richardson and Wisheart [20]. Dear et al. [21] studied the impact toughness of different lightweight sandwich panels and composite sheet materials. They emphasized on the degree of damage inflicted on the contact surface, through-thickness and rear surface of the materials when subjected to different impacts. Their aim is to develop lightweight stiff materials with enhanced structural integrity that can absorb higher impact energy. Vaidya et al. [22] studied composite sandwich structures composed of aluminum foam core and found it optimal for resisting low-velocity impacts. They also studied the vibration response of composite sandwich plates under a free-free-free-free boundary condition. They concluded that relationships can be established between the vibration response of the sandwich plate (natural frequency and damping ratio) and energy of impact. Similarly several novel sandwiches have been developed in scientific literature with a view to enhance the impact toughness [23-28].

In this paper we have made Low Velocity Impact (LVI) and post impact vibration tests to measure the impact resistance. More precisely we evaluated the resistance against impact of entangled sandwich materials in comparison with standard sandwiches with honeycomb and foam cores, is uniquely based on vibration test results i.e., decrease in natural frequency (global parameter of a structure) which signifies loss of rigidity and increase in damping which corresponds to friction in damaged zones. The authors want to clarify here, that impact toughness is only studied through vibration tests and the classical procedure used for determining the impact toughness i.e., Compression After Impact (CAI) has not been implemented as it is outside the scope of this work. Characterization of carbon and glass fiber entangled sandwich materials has been carried out both statically (compression and bending tests) and dynamically (vibration test) by Shahdin et al. [29,30]. Vibration tests verify the presence of high damping in the entangled sandwich specimens making them suitable for specific applications like the inner paneling of a helicopter cabin, even if the structural strength of this material is on the lower side. Shahdin et al. [31] also carried out the monitoring of impact damage in two types of carbon entangled sandwich beams (heavy and light). The light specimens have 2.5 times less resin than the heavy ones. Results show that the specimens with less resin are more sensitive to impact damage, have poorer static strength but on the other hand possess good damping capabilities. Unfortunately, little scientific literature can be found related to impact testing of entangled sandwich materials. One work that can be cited in this regard is that of Dean et al. [32]. Their paper documents an experimental and numerical study of energy absorption in lightweight sandwich panels with entangled stainless steel fiber cores. The results show that the sandwich panel absorbs $40 \%$ more energy than the two separated face plates with classical core.

As our research concerning entangled sandwich materials is still in the preliminary phase i.e., we do not master completely the fabrication process of entangled sandwiches, therefore for the instance comparison is only provided with standard sandwiches with honeycomb and foam cores. Comparison with enhanced sandwich structures e.g., honeycomb sandwiches with viscoelastic layer, etc is not in the scope of this work and shall be duly considered in future.

\section{Material and specimen}

Six sandwich beam specimens are studied in this article. The main emphasis of this article is on the two entangled sandwich beams with carbon and glass fibers as core materials. The honeycomb and foam sandwich beams are only presented for comparison purposes. As the entangled sandwich material being a relatively new material is in the 
Table 1

\begin{tabular}{lc}
$\begin{array}{l}\text { Physical properties of carbon/epoxy prepreg T700/M21 used as skin material in } \\
\text { carbon sandwich beams }\end{array}$ \\
\hline Homogenized elastic modulus in the longitudinal direction $\left(\mathrm{E}_{x}\right)$ & $67000 \mathrm{MPa}$ \\
Homogenized elastic modulus in the transverse direction $\left(\mathrm{E}_{y}\right)$ & $67000 \mathrm{MPa}$ \\
Shear Modulus $\left(\mathrm{G}_{12}\right)$ & $5000 \mathrm{MPa}$ \\
Poisson Ratio $\left(v_{12}\right)$ & 0.4 \\
Volume density $(\rho)$ & $1550 \mathrm{~kg} / \mathrm{m}^{3}$ \\
\hline
\end{tabular}

Table 2

Properties of glass woven fabric used as skin in glass sandwich beams

\begin{tabular}{ll}
\hline Elastic modulus in the longitudinal direction $\left(\mathrm{E}_{x}\right)$ & $23000 \mathrm{MPa}$ \\
Elastic modulus in the transverse direction $\left(\mathrm{E}_{y}\right)$ & $23000 \mathrm{MPa}$ \\
Shear modulus $(\mathrm{G})$ & $2900 \mathrm{MPa}$ \\
Poisson ratio $(v)$ & 0.098 \\
\hline
\end{tabular}

Table 3

Properties of Honeycomb core (Hexcel-aramid)

\begin{tabular}{ll}
\hline Cell size & $6.5 \mathrm{~mm}$ \\
\hline Density & $31 \mathrm{~kg} / \mathrm{m}^{3}$ \\
Compressive strength & $0.89 \mathrm{MPa}$ \\
Compressive modulus & $75.8 \mathrm{MPa}$ \\
Shear strength in longitudinal direction $\left(\sigma_{x z}\right)$ & $0.65 \mathrm{MPa}$ \\
Shear modulus in longitudinal direction $\left(\mathrm{G}_{x z}\right)$ & $29 \mathrm{MPa}$ \\
Shear strength in width direction $\left(\sigma_{y z}\right)$ & $0.31 \mathrm{MPa}$ \\
Shear modulus in width direction $\left(\mathrm{G}_{y z}\right)$ & $13.8 \mathrm{MPa}$ \\
\hline
\end{tabular}

phase of extensive research at this moment. Therefore comparison with standard sandwich beams is essential in order to evaluate the performance of entangled sandwich materials.

Three of the six sandwich beams have entangled carbon fiber, honeycomb and foam as core materials. For the skin, unidirectional carbon-fiber/epoxy prepregs of T700/M21 are used [33]. The prepreg sheets are supplied by Hexcel composites. The upper and lower skins consist of four plies each with a stacking sequence of [0/90/90/0]. The thickness of each ply is $0.125 \mathrm{~mm}$. The mechanical properties of the prepreg T700/M21 are given in Table 1 .

The other three sandwich beams have entangled glass fibers, honeycomb and foam as core materials. The skins of these three sandwich beams are made of glass woven fabric 20823 supplied by Hexcel composites as well. The glass woven fabric is impregnated with the help of epoxy resin. The epoxy resin SR 8100 and injection hardener SD 8824 are used provided by Sicomin. The upper and lower skins consist of two plies each with a total thickness of $0.5 \mathrm{~mm}$ containing $50 \%$ of resin. The thickness of the skins in case of glass woven fabric is kept similar to carbon fiber skins. The sandwich beam specimens are fabricated using an autoclave and an aluminum mold. The skin and the core are cured simultaneously in order to have an excellent bond. The physical properties of the glass woven fabric are set out in Table 2.

The honeycomb and foam cores can be selected from a wide range of metallic and non-metallic honeycomb cores and a variety of non-metallic foams. The honeycomb sandwich beams in this article are made of Nomex-aramid honeycomb core (HRH 10) supplied by Hexcel composites [34]. The honeycomb core has a nominal cell size of $6.5 \mathrm{~mm}$ and a core thickness of $10 \mathrm{~mm}$. In case of the foam sandwich beams, the foam core has also a thickness of $10 \mathrm{~mm}$ and is provided by Rohacell (material $51 \mathrm{~A}$ ). Mechanical properties of the honeycomb and foam cores are listed in Tables 3 and 4 respectively.

The core in case of the carbon entangled sandwich beam consists of carbon fibers (HTS-5631) that are made of a yarn of standard carbon filaments having a diameter of $7 \mu \mathrm{m}$. The length of the carbon fibers is $10 \mathrm{~mm}$ and their elastic modulus is $240 \mathrm{GPa}$. The fibers are provided by the company Toho-Tenax. In case of the glass entangled sandwich beam, the core consists of glass fibers made of glass filaments having a diameter of $14 \mu \mathrm{m}$. The length of the glass fibers is $10 \mathrm{~mm}$ with an elastic modulus of $73 \mathrm{GPa}$. The fibers are provided by the company PPG Fiber Glass Europe. For the cross-linking of carbon and glass fibers, epoxy resin SR 8100 and injection hardener SD 8824 are used provided by Sicomin as used in case of glass woven fabric for the skin material. A better vaporization is achieved if the resin is heated up to $35^{\circ} \mathrm{C}$ before being sprayed on the carbon and glass fibers. This allows the 
Table 4

Properties of Foam core (Rohacell 51A)

\begin{tabular}{lc}
\hline Density & $52 \mathrm{~kg} / \mathrm{m}^{3}$ \\
\hline Tensile strength & $1.9 \mathrm{MPa}$ \\
Compressive strength & $0.9 \mathrm{MPa}$ \\
Elastic modulus (traction) & $70 \mathrm{MPa}$ \\
Shear strength & $0.8 \mathrm{MPa}$ \\
Shear modulus & $19 \mathrm{MPa}$ \\
Elongation at break & $3.0 \%$ \\
\hline
\end{tabular}

Table 5

Properties of carbon and glass fibers used in the core of entangled sandwich beams

\begin{tabular}{ll}
\hline Type of carbon fiber & HTS-5631 \\
\hline Length of glass fiber & $10 \mathrm{~mm}$ \\
Diameter of carbon fiber & $7 \mu \mathrm{m}$ \\
Elastic modulus of carbon fiber & $240 \mathrm{GPa}$ \\
Type of glass fiber & Type E \\
Length of glass fiber & $10 \mathrm{~mm}$ \\
Diameter of glass fiber & $14 \mu \mathrm{m}$ \\
Elastic modulus of glass fiber & $73 \mathrm{GPa}$ \\
\hline
\end{tabular}

Table 6

Types and weight of the six sandwich beams tested in this article

\begin{tabular}{lc}
\hline Type of sandwich beam & Weight of sandwich beam $(\mathrm{g})$ \\
\hline Entangled Carbon & 63 \\
Honeycomb Carbon & 29 \\
Foam Carbon & 27 \\
Entangled Glass & 52 \\
Honeycomb Glass & 24 \\
Foam Glass & 29 \\
\hline
\end{tabular}
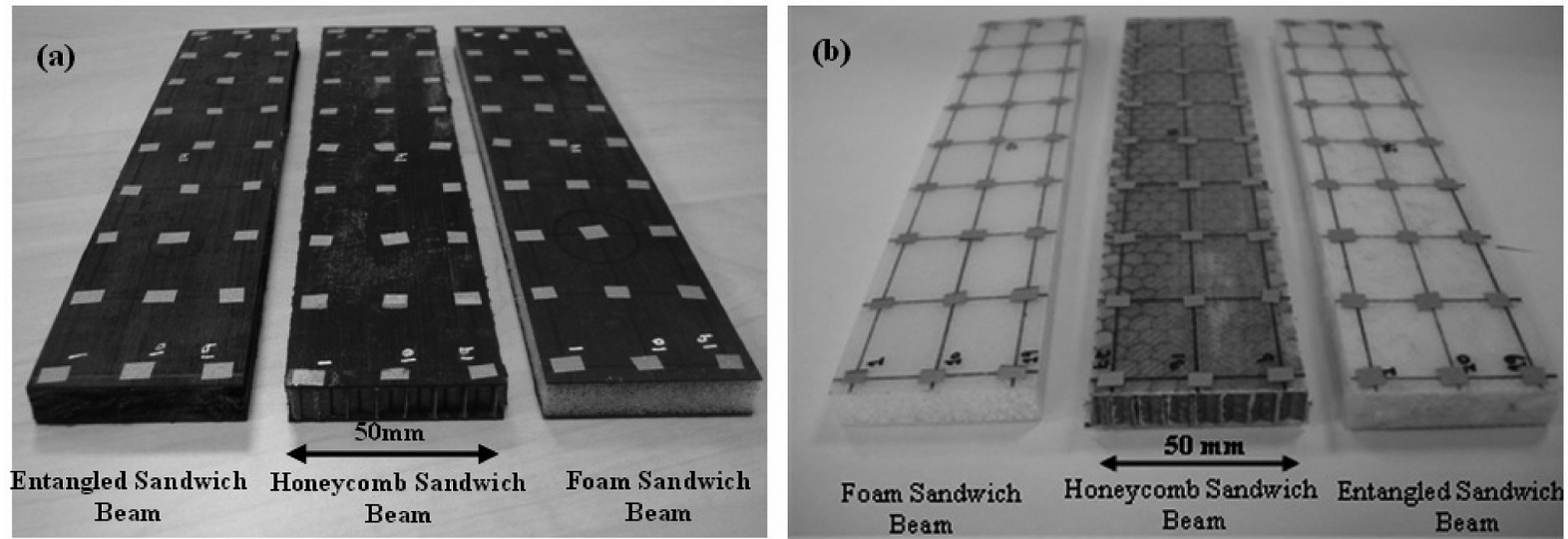

Fig. 1. The six sandwich beams tested in this article with (a) carbon prepregs and (b) glass woven fabric as skin materials.

mixture of resin and hardener to become less viscous. The properties of the carbon and glass fibers used in the core of entangled sandwich beams are presented in Table 5 .

All the test specimens presented in the article are carefully weighed using Mettler balance. The weights of the six sandwich beams are presented in Table 6 .

The fabrication of honeycomb and foam sandwich beams shall not be explained as the fabrication process is simple and very well known. However, the fabrication of entangled sandwich beams is a relatively complex process. The carbon and glass fibers are cut with the help of a fiber cutting machine supplied by Matrasur Composites. The fibers are then separated by a blow of compressed air. The mixture of resin and hardener is then sprayed on the separated glass fibers by a spray paint gun. The fibers vaporized by the resin are then placed in the mold between the two skins. To produce good quality sandwich beams reliably, cure cycle is adopted as follows: 1 hour from the ambient temperature to $125^{\circ} \mathrm{C}, 1.5$ hours at $125^{\circ} \mathrm{C}$ and 1 hour from $125^{\circ} \mathrm{C}$ to the ambient temperature. In case of the glass sandwich beam, the core has $26 \mathrm{~g}$ of glass fiber and $17 \mathrm{~g}$ of epoxy resin approximately. For the carbon sandwich beam, the core has $30 \mathrm{~g}$ of carbon fiber and $22 \mathrm{~g}$ of epoxy resin approximately. The same mold, cure cycle and skins are used for the fabrication of honeycomb and foam sandwich specimens. An aluminum mold $(300 \times 65$ 


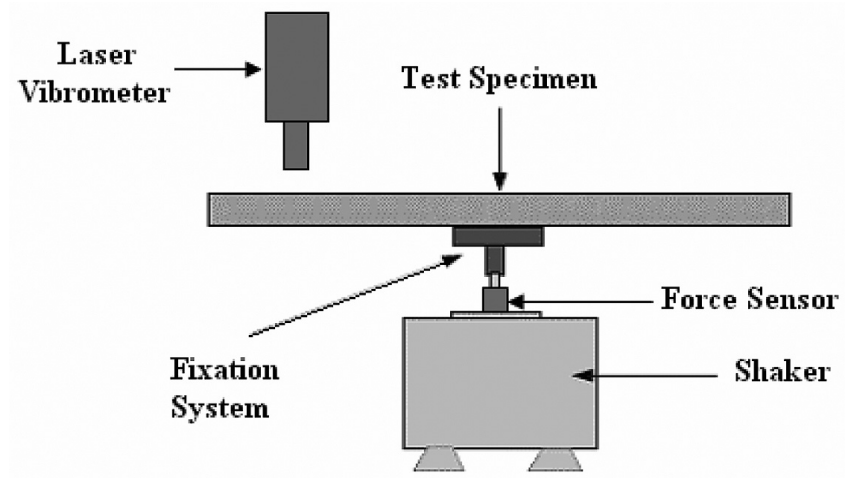

Fig. 2. Diagram of the experimental set-up.

$\times 11 \mathrm{~mm}$ ) is used for the fabrication. A fiber core density of approximately $200 \mathrm{~kg} / \mathrm{m}^{3}$ is chosen for the entangled sandwich core in case of both carbon and glass fibers.

The six sandwich test beams are shown in Fig. 1.

\section{Experimental methods}

\subsection{High quality vibration tests}

The experimental equipment used for vibration testing is shown in Fig. 2. The experimental set-up is that of a free-free beam excited at its center, based on Oberst method [35]. The Oberst method states that a free-free beam excited at its center has the same dynamical behavior as that of a half length cantilever beam. The test specimen is placed at its center on a B\&K force sensor (type 8200) which is then assembled on a shaker supplied by Prodera (type EX) having a maximum force of $100 \mathrm{~N}$. However the force sensor is not capable of measuring reliable response below $5 \mathrm{~Hz}$. A fixation system is used to place the test specimens on the force sensor. The fixation is glued to the test specimens with a HBM X60 rapid adhesive. The response displacements are measured with the help of a non-contact and high precision Laser Vibrometer OFV-505 provided by Polytec. The shaker, force sensor and the laser vibrometer are manipulated with the help of a data acquisition system supplied by LMS Test Lab for burst random testing and Ideas Test $(\mathrm{B} \& \mathrm{~K})$ for sine dwell testing.

The center of the test specimens is excited at Point 14 as shown in Fig. 3. Each sandwich specimen is tested with two types of excitations i.e., burst random and sine dwell. For both the testing systems (LMS and B\&K), the resolution is kept $0.25 \mathrm{~Hz}$ to allow a good shape of the resonance peaks at low frequency range and to have a reliable comparison of modal parameters between the two systems. Response is measured at 27 points that are symmetrically spaced in three rows along the length of the beam to have reliable identifiable mode shapes. The level of the excitation signal for both the excitations is chosen as $1 \mathrm{~N}$ which is kept fixed during all the vibration tests conducted in this paper. With the help of LMS by using burst random excitation, we have the advantage of having in quick time the overall dynamic (modal) response of our structure if we are mostly concerned with frequency and mode shapes. In addition, this broadband type of testing helps us identify the modes that we can use later on for sine-dwell testing. However if we need precise damping measurements then sine-dwell testing becomes inevitable but the problem with it is the lengthy acquisition times.

Burst random excitation is a broadband type excitation signal. 50\% burst percentage is used for burst random excitation. Normally burst random excitations are leakage free but the first author after trying different window functions found out that by putting Hanning windows on both the excitation and response signals, better quality signals FRFs are obtained. The signal is averaged 10 times for each measurement point and the frequency band chosen is $0-2650 \mathrm{~Hz}$. Disadvantages of burst random excitation are that they remove distortion, have a medium signal to noise ratio and are not able to characterize nonlinearity [37]. Jumping phenomenon (Sine dwell test with sweeping frequency up and down) is another indication of nonlinear vibration due to damage [38]. 


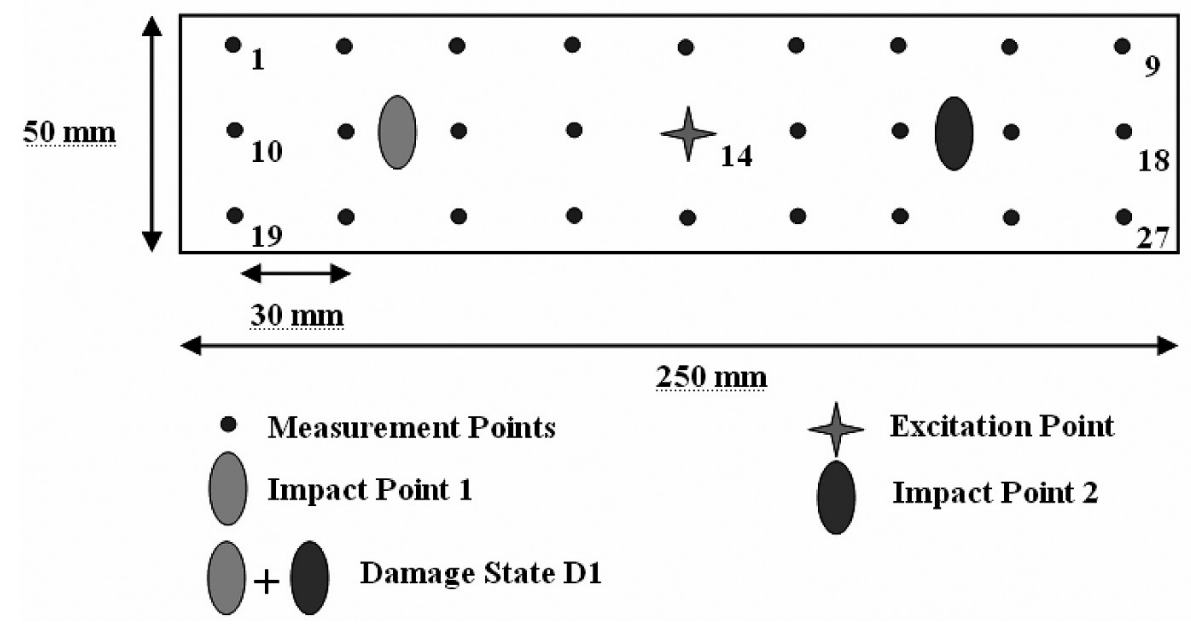

Fig. 3. Sandwich test beams with location of the two impact points, 27 measurement points and one excitation point (Point 14).

Sine-dwell excitation is the discrete version of sine sweep. The frequency is not varied continuously, but is incremented by discrete amounts at discrete time points. The advantage of sine-dwell testing is its capability of detecting non linear structural dynamic behavior unlike the broadband excitations i.e., with sine dwell excitation we can differentiate between linear and non-linear effects because the excitation is at a single frequency [36]. As sine dwell testing requires larger acquisition times, so instead of studying the whole frequency band $(0-2650 \mathrm{~Hz})$, acquisition is carried out only around the first four bending modes previously identified by burst random testing by keeping the same resolution.

The modal parameters are extracted with the help of Polymax and Polyreference, integrated in the data acquisition systems, for burst random and sine-dwell testing respectively. The Polymax estimation method used by LMS acquisition system is a new non-iterative frequency domain parameter estimation method based on weighted least squares approach. This Polymax least-squares complex frequency domain method is implemented in a very similar way as the industry standard Polyreference used by B\&K system, which is a time domain least squares frequency domain method. Both of these methods work in similar fashion as follows:

- First the sum of 27 FRFs is computed, and then resonance peaks with MIF indicator are compared.

- A reduced band around each resonance is selected separately. In order to have a consistent assessment of damping, a frequency interval of $\pm 20 \mathrm{~Hz}$ is chosen for each resonance peak for both Polymax and Polyreference. It has been observed that by changing the frequency interval damping values can be affected.

- Polymax and Polyreference stability diagrams are used to ensure the accuracy of the extracted modal parameters. For reliable damping measurement, that value of pole should be chosen which displays a stable value for several model orders. If possible, for each mode, the value of poles should be chosen at the same model order, to ensure that there is minimum uncertainty while comparing the damping values between the different damage states.

One of the specific advantages of these two techniques lies in the very stable identification of the system poles and participation factors as a function of the specified system order, leading to easy-to-interpret stabilization diagrams. This implies a potential for automating the method and to apply it to "difficult" estimation cases such as high-order and/or highly damped systems with large modal overlap. As discussed previously, both Polymax and Polyreference are based on least-squares complex optimization methods, so both of them calculate the optimal pole value (frequency and damping) based on the 27 measurement points. We do not have access to the average values, variances or standard deviations for the 27 FRFs as the estimated modal parameters are the results of an optimized process. The reference [39] explains these two estimators in detail.

So from the above discussion it can be said that both Polymax and Polyreference methods work in similar fashion, so the difference in the resulting modal parameters if it is the case, is due to the difference in excitations than due to the different estimation methods. 
Table 7

Impact test parameters of the sandwich beams

\begin{tabular}{lcccc}
\hline Type of specimen & $\begin{array}{c}\text { Energy of impact } \\
\text { measured }(\mathrm{J})\end{array}$ & \multicolumn{2}{c}{$\begin{array}{c}\text { Indentation just after } \\
\text { impact }(\mathrm{mm})\end{array}$} & \multirow{2}{*}{$\begin{array}{c}\text { Velocity of impact } \\
\text { measured (m/s) }\end{array}$} \\
\cline { 3 - 4 } & & Point 1 & Point 2 & \\
\hline Entangled Carbon & 4.9 & 0.1 & 0.15 & 2.21 \\
Honeycomb Carbon & 3.9 & 0.1 & 0.5 & 1.98 \\
Foam Carbon & 3.8 & 0.1 & 0.2 & 1.98 \\
Entangled Glass & 6.2 & 0.2 & 0.15 & 2.49 \\
Honeycomb Glass & 3.8 & 0.2 & 0.4 & 1.98 \\
Foam Glass & 3.8 & 0.15 & 0.25 & 1.98 \\
\hline
\end{tabular}

Force charge meter

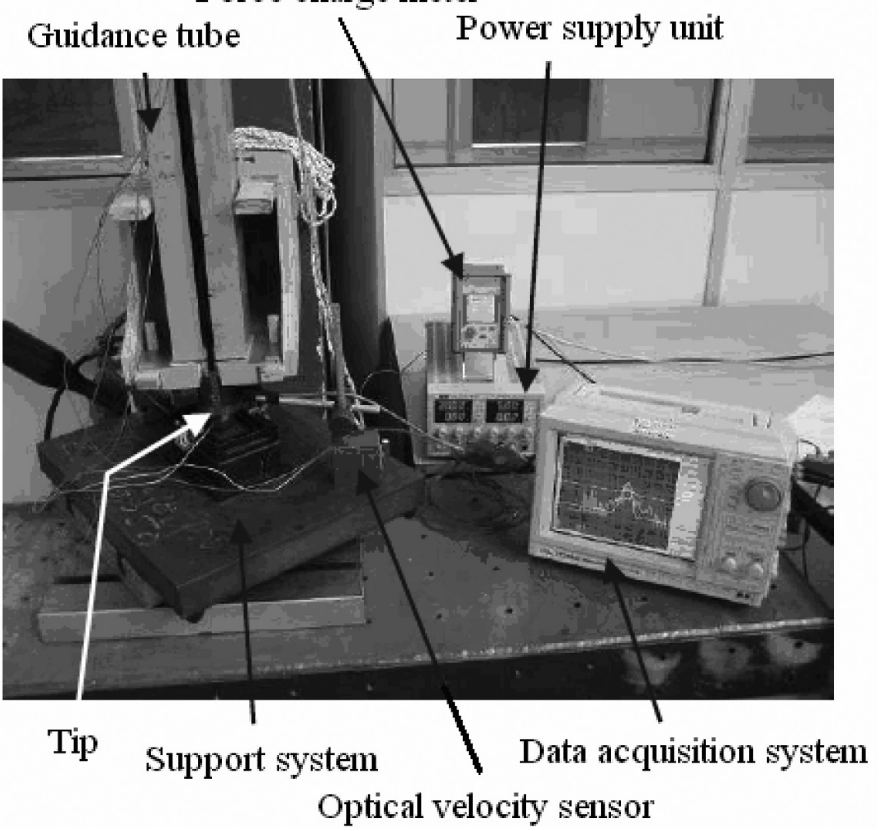

Fig. 4. Arrangement of the test equipment for the impact test.

\subsection{Low velocity impact tests}

The six sandwich beams tested in this article are damaged by drop weight impacts below the barely visible impact damage limit (BVID), in order to simulate damage by foreign impact objects such as stones or birds. The impact tests are carried out by a drop weight system as shown in Fig. 4, and a detailed cut away of the drop assembly is shown in Fig. 5.

The impactor tip has a hemispherical head with a diameter of $12.7 \mathrm{~mm}$. A force sensor (type 9051A) provided by Kistler is placed between the impactor tip and the free falling mass of $2 \mathrm{~kg}$. The velocity before the impact is measured with the help of an optical velocity sensor from which the energy of impact can be verified. The combined weight of the impact head, freefalling mass, force sensor and the accelerometer is $2.03 \mathrm{~kg}$. The size of the impact window is $80 \times 40 \mathrm{~mm}^{2}$ which allows all the impact points to have the same boundary conditions and all the four ends are fully clamped. Further details on the impact test methodology of this drop tower can be found in the references [3,4].

A simple case of symmetrical impacts is studied in this article as unfortunately very little literature is available regarding impact tests on entangled sandwich materials. If satisfactory results are obtained, then asymmetric damage shall be studied in the future. The sandwich beams are impacted by taking into account the barely visible impact damage limit (BVID). BVID corresponds to the formation of an indentation on the surface of the structure that can 


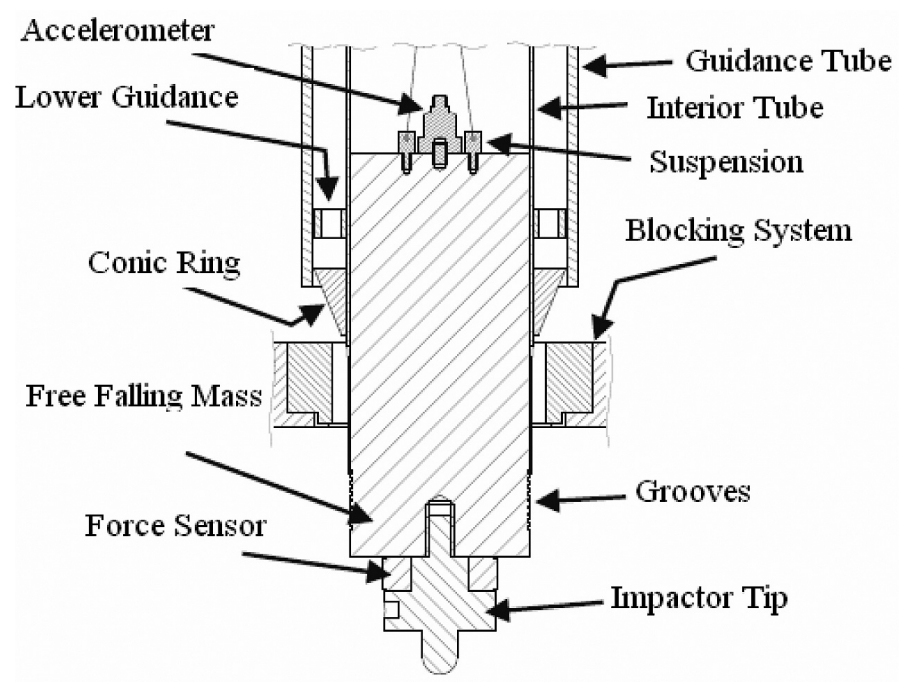

Fig. 5. Detailed cutaway of the drop assembly, the guidance tube and the blocking system.

be detected by detailed visual inspection and can indicate high damage. In the aeronautical domain, BVID means an indentation of $0.3 \mathrm{~mm}$ after relaxation, aging etc. (according to Airbus certifications). In this study, it is decided to take $0.6-0.8 \mathrm{~mm}$ of penetration depth as detectability criterion just after the impact [3,4] which corresponds to an indentation depth of approximately $0.3 \mathrm{~mm}$ by taking into account the above mentioned factors such as relaxation, aging, humidity etc. The idea behind the impact tests is to damage the specimens below the BVID limit, in order to detect by vibration testing the damage that is not visible through naked eye.

However in case of honeycomb sandwich beams, it is difficult to induce the same amount of damage at different points in the same specimen, even if it is impacted with the same energy i.e., impacting at the honeycomb cell center and at the corner leads to different damages. Therefore, it is not possible to have the same density of damage in the honeycomb sandwich beams at the two impact points. This phenomenon is explained by taking the example of the carbon honeycomb sandwich beam impacted at $4 \mathrm{~J}$ shown in Fig. 6. The indentation depth at the impact point 1 is $0.1 \mathrm{~mm}$ due to impact at the honeycomb cell corner. Whereas the indentation depth at the impact point 2 is $0.5 \mathrm{~mm}$ because the impactor head has induced severe damage due to impact at honeycomb cell center. This phenomenon introduces asymmetry in the beams and highlights the difficulty in inducing a global symmetric damage.

The impact energy is chosen in such a way that each sandwich beam has approximately the same level of damage i.e., below the BVID limit which is nearly invisible on the surface. The impact parameters and the indentation depths measured for the six sandwich beams are listed in Table 7. It shall be noticed that the dispersion in damage between the two impact points is smaller in case of the entangled and foam sandwich beams as compared to the honeycomb sandwich beams due to the phenomenon explained above.

The data obtained during the drop weight impact tests carried out on the six sandwich beams is presented in Fig. 7.

Two similar impacts have been performed on each sandwich beam. However, in order to clarify these plots, the three glass and three carbon sandwich beams are plotted separately and in addition, only one impact test result for each specimen is plotted. All the impact curves presented in Fig. 7 are low-pass filtered at $15 \mathrm{kHz}$ to avoid a free frequency of the impactor at about $20 \mathrm{kHz}$. These curves, representative of all performed impact tests, are very classic in the literature [3-5]. In Fig. 7a and 7b, the impact forces are drawn as a function of time for the six sandwich beams. These curves are globally smooth and almost sinusoidal at low impact energy. It can also be seen, from the force-displacement plots of both the carbon and glass sandwich beams (Fig. 7c and 7d), that after the first damage in the classical sandwiches with honeycomb and foam cores there is a decrease in the force signal followed by oscillations which signifies damage and loss of rigidity in the material. But in case of both glass and carbon fiber entangled sandwich beams (Fig. 7c and 7d), after the appearance of first damage the material continues to rigidify which is shown by a progressive increase of force signal. If we speak in terms of energy dissipation, it can be observed from the force displacement curves of the honeycomb and foam core sandwiches (Fig. 7c and 7d) 


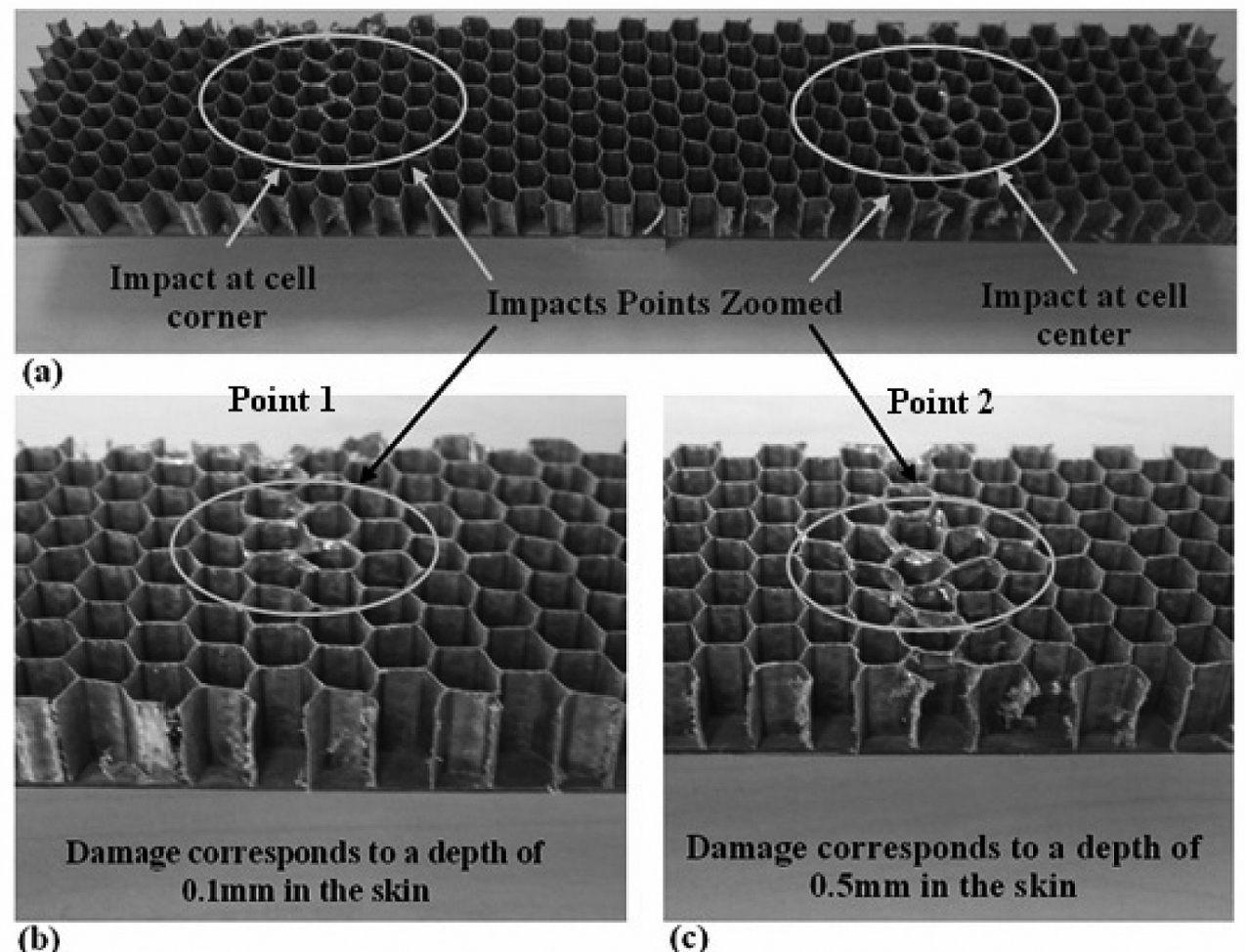

(b)

(c)

Fig. 6. Dispersion of damage between the two impact points in case of honeycomb carbon beam, impacted at $4 \mathrm{~J}$.

that the energy dissipation seems mostly due to the rupture mechanism. However in case of entangled sandwiches the behavior is different, it is possible that the energy dissipation might be predominantly due to damping as no oscillations or force signal loss is observed i.e., no apparent damage signs.

This behavior can also be seen on the stress-strain curves of compression tests which are very classical in scientific literature $[29,30]$. Compression test results in case of standard sandwiches with honeycomb and foam cores exhibit that there is a progressive decrease in the stress level once the maximum elastic limit is attained. However for the entangled sandwiches, normally there is a densification phase after the maximum elastic limit which explains the rigid nature of the entangled sandwiches as compared to the honeycomb and foam sandwich beams tested in this paper. This rigid nature of entangled sandwich beams is also verified further ahead in this article while evaluating the resistance against impact by shifts in natural frequency.

The sandwich beams tested in this paper have two states. First one is the undamaged state (UD) and the second is the damage state due to two impacts (D1). Vibration tests are carried out on the six sandwich beams after each of these two states. The effect of impact damage on the modal parameters of the three types of sandwich beams is studied in the following sections of this paper with the help of frequency and damping changes between the undamaged (UD) and the damaged case (D1) with the help of Eqs (1) and (2).

$$
\begin{aligned}
& \text { Change in frequency between UD and D1, } \Delta f=\frac{f_{D 1}(k)-f_{U D}(k)}{f_{U D}(k)} \\
& \text { Change in damping between UD and D1, } \Delta \zeta=\frac{\zeta_{D 1}(k)-\zeta_{U D}(k)}{\zeta_{U D}(k)}
\end{aligned}
$$

where $f_{U D}(k)$ is the damped natural frequency for the undamaged specimen for the $k_{t h}$ mode and $f_{D 1}(k)$ is the damped natural frequency for the specimen damaged at two impact points (D1) for the $k_{t h}$ mode. Nomenclature in case of Eq. (2) is the same. 

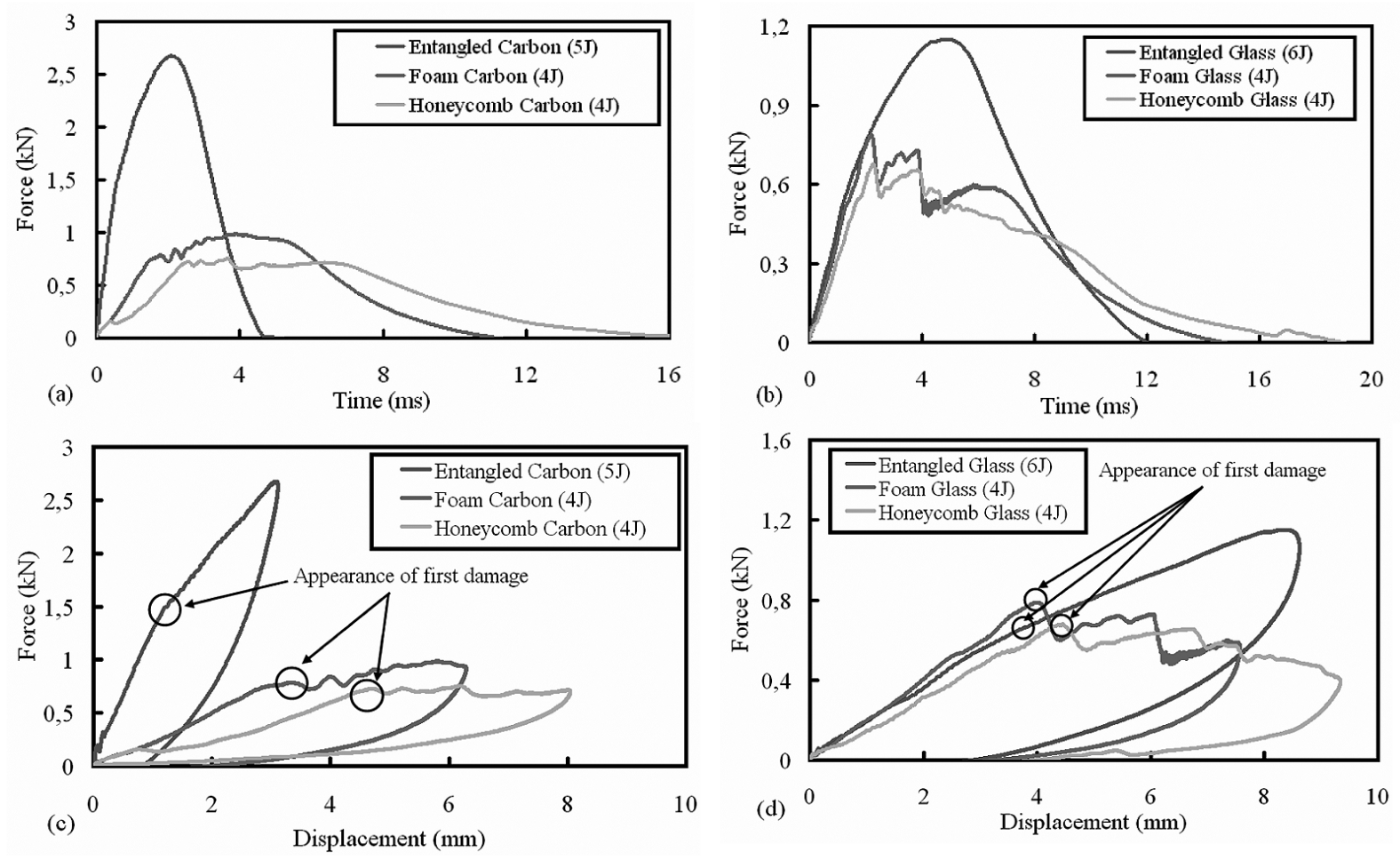

Fig. 7. Impact test data (a,b) force-time (c,d) force-displacement for each sandwich beams type: carbon (a,c) and glass (b,d).

\subsection{Shift in modal parameters due to damage}

Modal parameter estimation is a special case of system identification where the a priori model of the system is known to be in the form of modal parameters. The identification process consists of estimating the modal parameters from frequency response function (FRF) measurements. Modal identification uses numerical techniques to separate the contributions of individual modes of vibration in measurements such as frequency response functions. Each term of the FRF matrix can be represented in terms of pole location and a mode shape. The FRF matrix model is represented mathematically by:

$$
[H(\omega)]=\sum_{k=1}^{\text {modes }}\left\{\frac{[R(k)]}{(j \omega(k)-p(k))}+\frac{[R(k) *]}{(j \omega(k)-p(k) *)}\right\}
$$

The numerator $R(k)$ is the residue of the FRF and is a function of the product between mode shape components at all points. The denominator gives the modal frequency and modal damping (second term in Eq. (3) is the complex conjugate term also known as poles). The poles $p(k)$, are the roots that satisfy this equation and are related to modal frequency and damping as follows:

$$
p(k)=-\sigma(k)+j \omega(k)
$$

The magnitude of each pole is the undamped natural frequency $\left(\omega_{n}\right)$. The undamped natural frequency $\left(\omega_{n}\right)$ is related to the modal damped frequency $\left(\omega_{d}\right)$ and the modal damping $(\sigma)$ and also to the mass, stiffness and damping as follows:

$$
\begin{aligned}
& \omega_{n}=\sqrt{\omega_{d}^{2}+\sigma(k)^{2}}=\sqrt{\frac{K}{M}} \\
& 2 \sigma(k)=\frac{C}{M}
\end{aligned}
$$




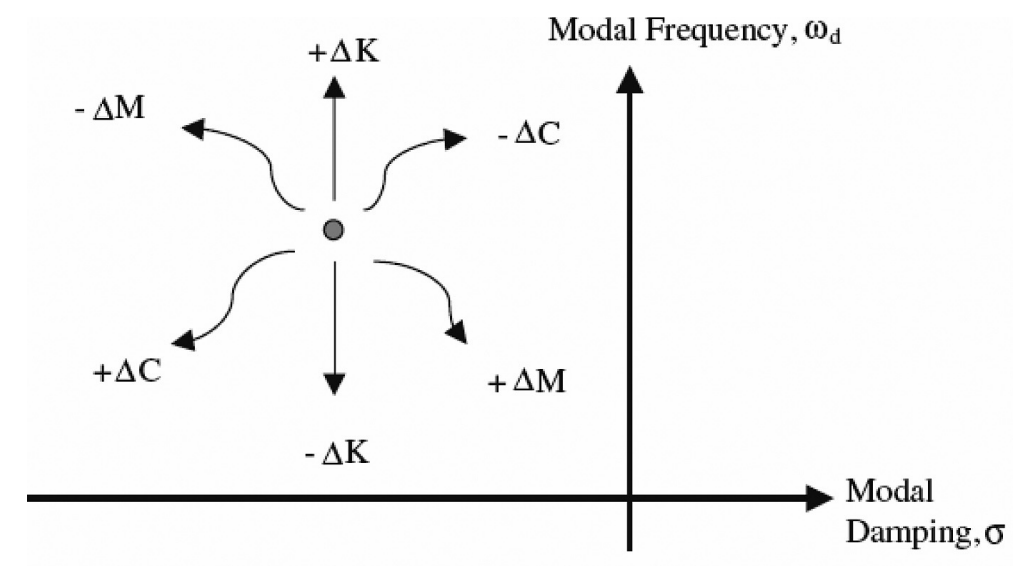

Fig. 8. Movement of pole due to mass stiffness and damping effect.

The effect of physical properties on poles in the complex s-plane is illustrated in Fig. 8.

From Fig. 8, it can be observed that a change in stiffness affects only the frequency, while changes in mass and structural damping affect both modal damped frequency $\left(\omega_{d}\right)$ and modal damping $(\sigma)$. For this study, the primary interest is to study the decrease in the modal damped frequency $\left(\omega_{d}\right)$ and the increase in modal damping $(\sigma)$ due to damage in the sandwich specimens [40].

\section{Results and discussions}

\subsection{Effect of impact damage on modal parameters}

The effect of impact damage on the three types of sandwich beams is studied with the help of modal parameter shifts for the first three bending modes, as they have the largest amplitudes for the type of test configuration presented in this article. Frequency and damping ratios are the global parameters of the specimen, and are extracted from high quality measurements carried out on the 27 measurement points. The modal parameters (natural frequency and damping) help in monitoring globally the health of a specimen. For the first three bending modes, the variation of damped natural frequency as a function of the undamaged (UD) and the damage state (D1) for the six sandwich beams for both burst random (BR) and sine-dwell (SD) testing is presented in Fig. 9.

Figure 9 shows that as a result of impact damage, there is a decrease in the natural frequencies for the six sandwich beams as discussed before in Section 3.3. It can be noticed that this decrease is less prominent in case of both the carbon and glass entangled sandwich beams as compared to the honeycomb and foam sandwich beams. It is also evident from Fig. 9 that in case of natural frequencies, both burst random and sine-dwell testing give similar results. But the interesting fact is that for all the sandwich beams, even as the impact damage does not produce a visible damage on the surface, the change in frequency between the undamaged and the damaged cases is quite noticeable. This proves that there is a notable loss of rigidity without any signs of damage on the surface (with the exception of some impact points in case of honeycomb sandwich beams as discussed previously). It is particularly in these cases that vibration testing becomes a very useful tool for damage detection.

The fact that the change in natural frequency between the damaged and the undamaged case is small in the entangled beams as compared to the foam and honeycomb beams can be seen in Fig. 10, which presents a comparison between the frequency response functions of the undamaged and the damaged cases for the six sandwich beams for the 1st bending mode. The frequency response functions presented in Fig. 10 are obtained with the help of sine-dwell testing. For the six sandwich beams, it can be concluded that the shift in natural frequencies is slight in case of entangled sandwich beams proving that they have a loss of rigidity that is less pronounced as compared to the honeycomb and foam sandwich beams. Furthermore in case of the three carbon sandwich beams (Fig. 10a), the frequency response functions of the carbon entangled sandwich beam are more acute (smaller in width) as compared 

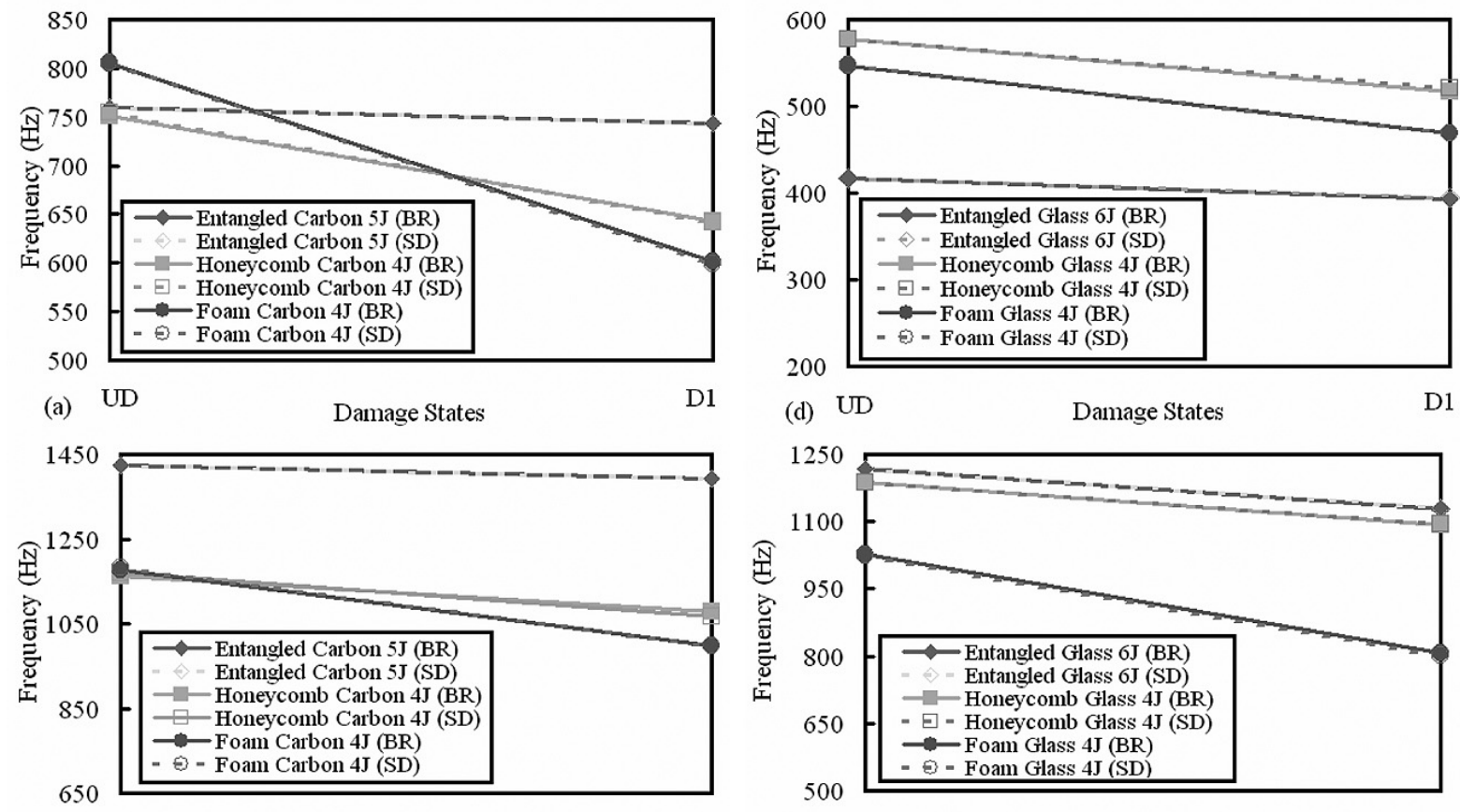

(b) UD

Damage States

D1

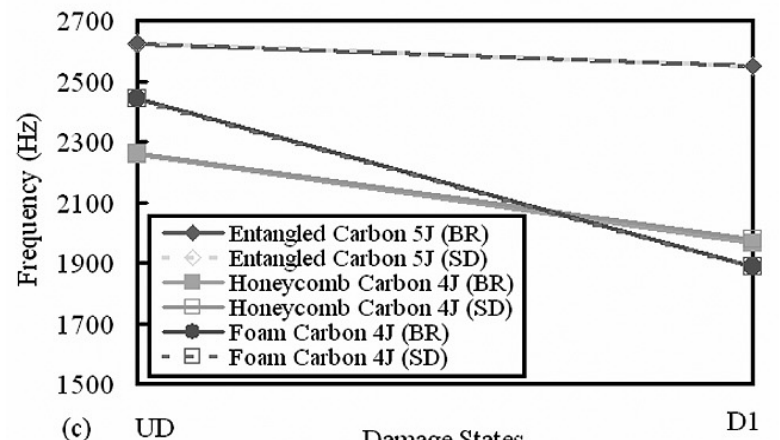

(e) UD

Damage States

D1

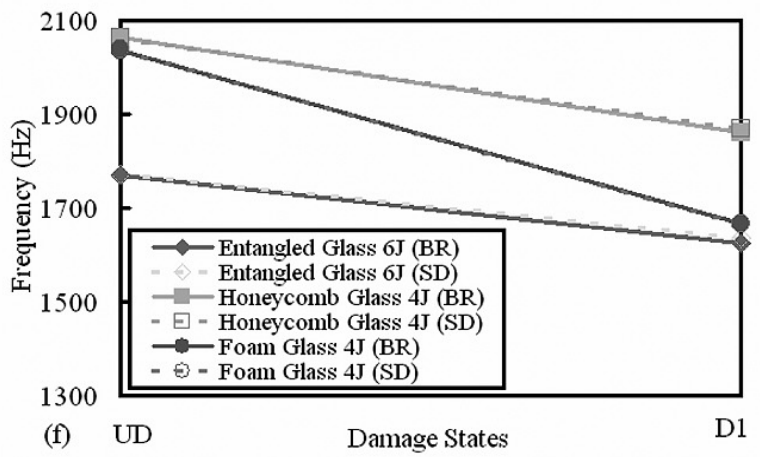

Fig. 9. Variation of damped natural frequencies with damage states for (a) 1st bending mode, (b) 2nd bending mode and (c) 3rd bending mode for the carbon sandwich beams and (d) 1st bending mode, (e) 2nd bending mode and (f) 3rd bending mode for the glass sandwich beams: UD is undamaged state, D1 is damaged at 2 impact points for both burst random (BR) and sine-dwell (SD) testing.

to the honeycomb and foam sandwich beams. This phenomenon is less evident in case of the glass entangled sandwich beams (Fig. 10b).

It is noticed that in case of honeycomb sandwich beams, the level of damage is not the same on both sides of the beams as it depends on whether the honeycomb cell center or corner is impacted as discussed previously and shown in Fig. 6. So this asymmetric damage leads to distortion of the resonance peaks or the appearance of twin peaks instead of one. This is evident in Fig. 11, which shows a comparison of the sum of the frequency response functions (FRF), estimated by burst random testing, for the six sandwich beams for the undamaged (UD) and the damaged cases (D1) for the 3rd bending mode. The sum of the FRF can be compared as for each sandwich beam 27 symmetric measurement points have been chosen that are symmetric on both sides of the two major axes of symmetry.

Figure $11 \mathrm{~b}$ and $11 \mathrm{e}$ show that in case of honeycomb sandwich beams due to asymmetric distribution of damage the shape of peaks become distorted. A slight distortion of peak is also observed in case of the entangled glass beam in Fig. 11d. But on the whole for the entangled and foam sandwich beams the damage is pretty much symmetric and peaks remain intact. Both burst random and sine-dwell testing give similar natural frequency results in the 
Table 8

Frequency change ratios (\%) between the undamaged (UD) and the two damaged states (D1 and D2) for the carbon and glass sandwich beams for both burst random (BR) and sine dwell (SD) testing

\begin{tabular}{|c|c|c|c|c|c|c|c|}
\hline \multirow[t]{2}{*}{ Type of specimens } & \multirow[t]{2}{*}{ Between states } & \multicolumn{2}{|c|}{ Mode 1} & \multicolumn{2}{|c|}{ Mode 2} & \multicolumn{2}{|c|}{ Mode 3} \\
\hline & & $\mathrm{BR}$ & $\mathrm{SD}$ & $\mathrm{BR}$ & $\mathrm{SD}$ & $\mathrm{BR}$ & $\mathrm{SD}$ \\
\hline Foam Glass (4J) & UD and D1 & 14.2 & 14.2 & 21.4 & 21.6 & 18.0 & 18.2 \\
\hline Honeycomb Glass (4J) & UD and D1 & 10.4 & 9.7 & 8.0 & 7.9 & 9.7 & 9.4 \\
\hline Entangled Glass $(6 \mathrm{~J})$ & UD and D1 & 5.8 & 5.5 & 7.2 & 7.1 & 8.2 & 7.6 \\
\hline Foam Carbon $(4 \mathrm{~J})$ & UD and D1 & 25.2 & 25.6 & 15.3 & 15.5 & 22.6 & 22.7 \\
\hline Honeycomb Carbon (4J) & UD and D1 & 14.4 & 14.9 & 7.2 & 8.6 & 12.8 & 12.4 \\
\hline Entangled Carbon (5J) & UD and D1 & 2.2 & 2.2 & 2.1 & 2.2 & 2.8 & 2.9 \\
\hline
\end{tabular}
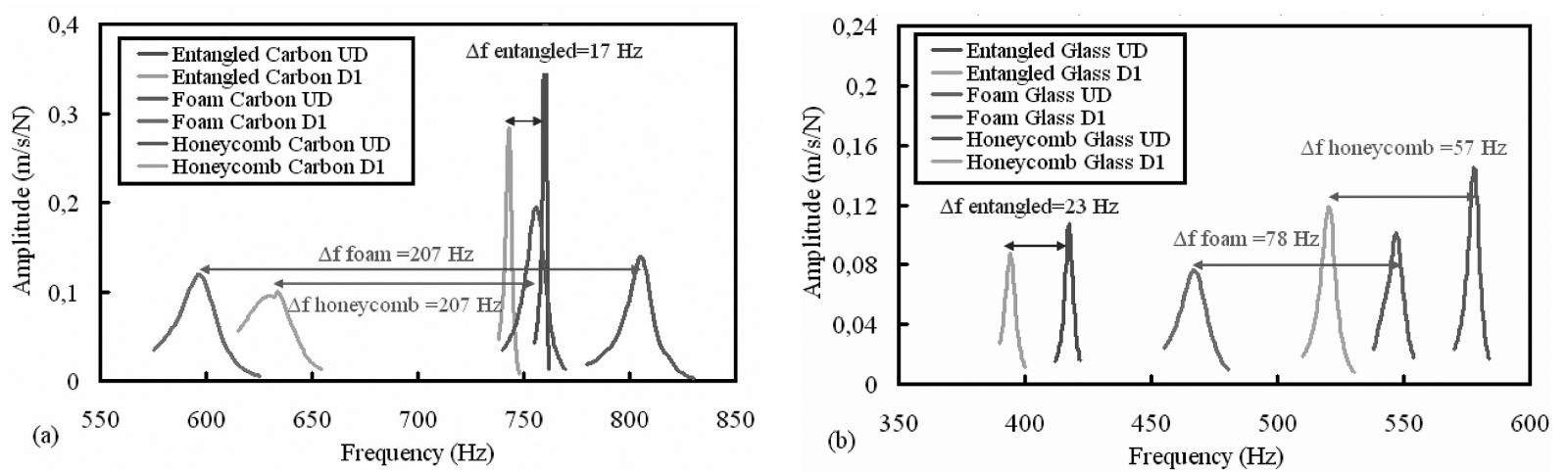

Fig. 10. Comparison of the frequency response functions estimated by sine-dwell testing for the undamaged case (UD) and damaged at 2 points (D1) for the 1st bending mode for (a) Point 11 for the three carbon sandwich beams and for (b) Point 21 for the three glass sandwich beams.

presence of damage. It can be said that frequency estimation is then reliable and so on we are able to detect damages from frequency shifts in the FRF. Estimating damping with reliability is more difficult [41]; therefore we have used two Modal Parameter Estimators, i.e., Polymax in the frequency domain and Polyreference in the time domain. Both algorithms are based on least-squares optimization on 27 experimental FRFs, to fit poles from analytical data (complex conjugate poles of Eq. (3)) with experimental FRFs. Finally damping ratios can be viewed as equivalent linearized damping ratios. However, for the estimation of damping ratios for the damage state D1, there is a notable difference between the results of burst random and sine dwell testing as shown in Fig. 12, because sine dwell excitation can differentiate between the linear and non-linear effects as the excitation is at a unique frequency.

It can be seen in Fig. 12 that in general the damping increases with the increase in damage in the sandwich beams. Nonetheless in case of burst random testing, for the carbon entangled and the carbon honeycomb sandwich beams (Fig. 12b) and for the carbon foam sandwich beam (Fig. 12c), the damping decreases with damage. However sine dwell testing shows a logical increase of damping for these beams. Furthermore, the estimation of damping by sine-dwell testing for the damage state (D1) is always notably higher as compared to burst random testing. It can be said that sine dwell testing is more capable of detecting non linear structural dynamic behavior (due to accumulation of damage as in state D1) unlike the broadband excitations. Furthermore, the change in damping ratios between the undamaged and the damaged case is smaller again in case of entangled sandwich beams. Therefore it can be concluded that the entangled sandwich beams show a better resistance to impact as compared to the honeycomb and foam sandwich beams, whereas all the beams have more or less the same level damage. This trend verifies somewhat the results of the impact tests carried out on these sandwich beams in Section 3.2. By taking into consideration these results, in terms of application the authors think that the entangled sandwich materials can replace the aluminum parts at the wing tips used to resist impact, as these aluminum parts are not load carriers. Hence the entangled materials can be used in these types of specific applications where static strength is not required but the main objective is the resistance to impact.

The effect of impact damage on the natural frequencies and damping ratios can be further elaborated by studying the frequency and the damping change ratios presented in Tables 8 and 9 between the undamaged (UD) and the damaged case (D1) for the six sandwich beams based on Eqs (1) and (2). 
Table 9

Damping change ratios (\%) between the undamaged (UD) and the two damaged states (D1 and D2) for the carbon and glass sandwich beams for both burst random (BR) and sine dwell (SD) testing

\begin{tabular}{|c|c|c|c|c|c|c|c|}
\hline \multirow[t]{2}{*}{ Type of specimens } & \multirow[t]{2}{*}{ Between states } & \multicolumn{2}{|c|}{ Mode 1} & \multicolumn{2}{|c|}{ Mode 2} & \multicolumn{2}{|c|}{ Mode 3} \\
\hline & & BR & $\mathrm{SD}$ & $\begin{array}{l}\mathrm{BR} \\
\end{array}$ & $\mathrm{SD}$ & BR & $\mathrm{SD}$ \\
\hline Foam Glass (4J) & UD and D1 & 57.7 & 106.0 & 140.7 & 216.1 & 260.3 & 308.7 \\
\hline Honeycomb Glass (4J) & UD and D1 & 18.1 & 32.7 & 22.0 & 32.9 & 64.1 & 72.6 \\
\hline Entangled Glass (6J) & UD and D1 & 11.4 & 44.4 & 19.1 & 29.1 & 4.5 & 16.1 \\
\hline Foam Carbon (4J) & UD and D1 & 119.3 & 204.3 & 26.3 & 21.5 & -55.9 & 70.8 \\
\hline Honeycomb Carbon (4J) & UD and D1 & 35.7 & 156.2 & -49.4 & 2.01 & 32.3 & 37.5 \\
\hline Entangled Carbon (5J) & UD and D1 & 38.5 & 79.3 & -3.5 & 19.1 & 4.1 & 31.1 \\
\hline
\end{tabular}
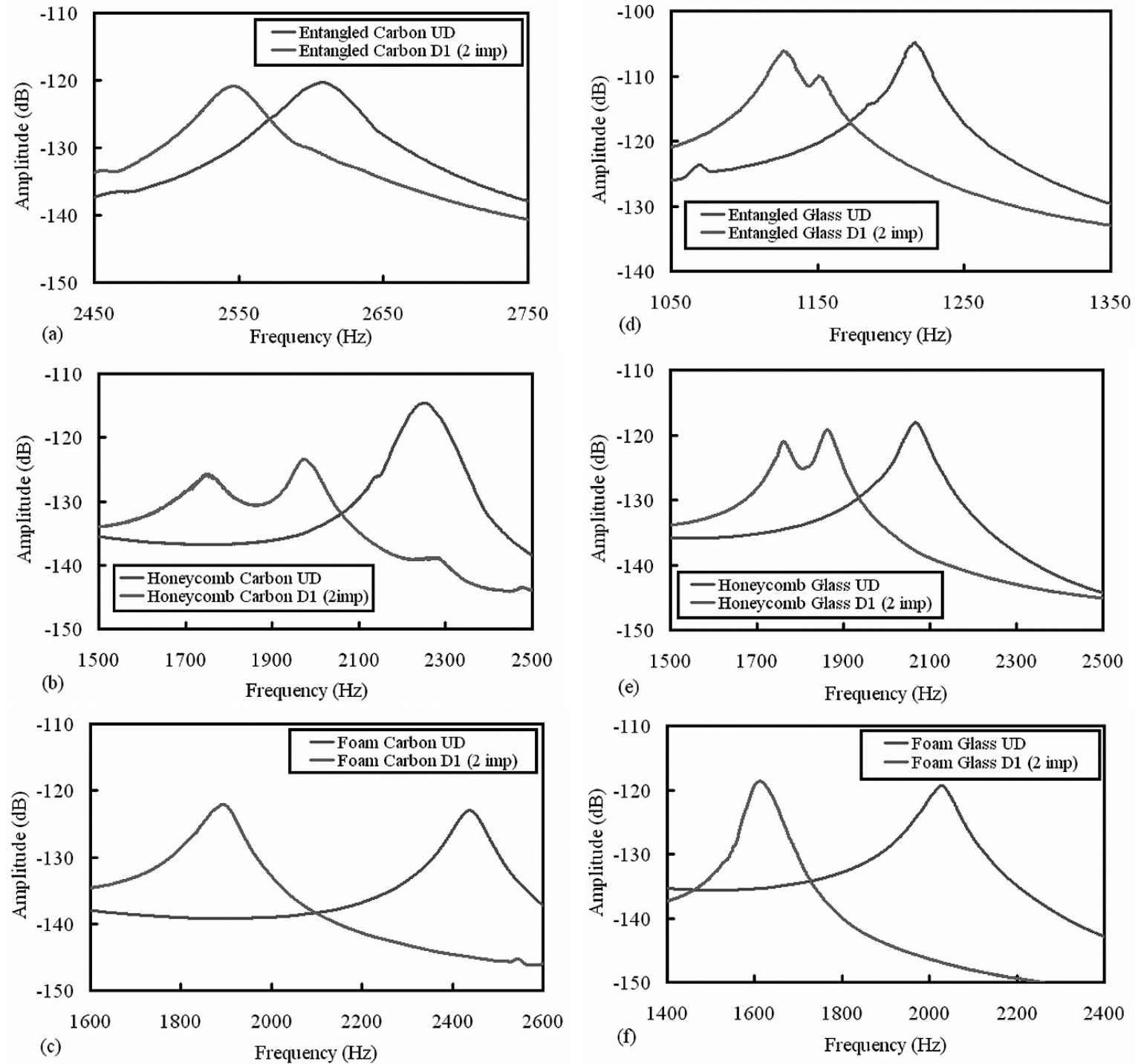

Fig. 11. Comparison of the sum of the frequency response functions estimated by burst random testing for the undamaged case (UD) and damaged case (D1) for the 3rd bending mode for (a) entangled carbon (b) honeycomb carbon (c) foam carbon (d) entangled glass (e) honeycomb glass (f) foam glass sandwich beams. 

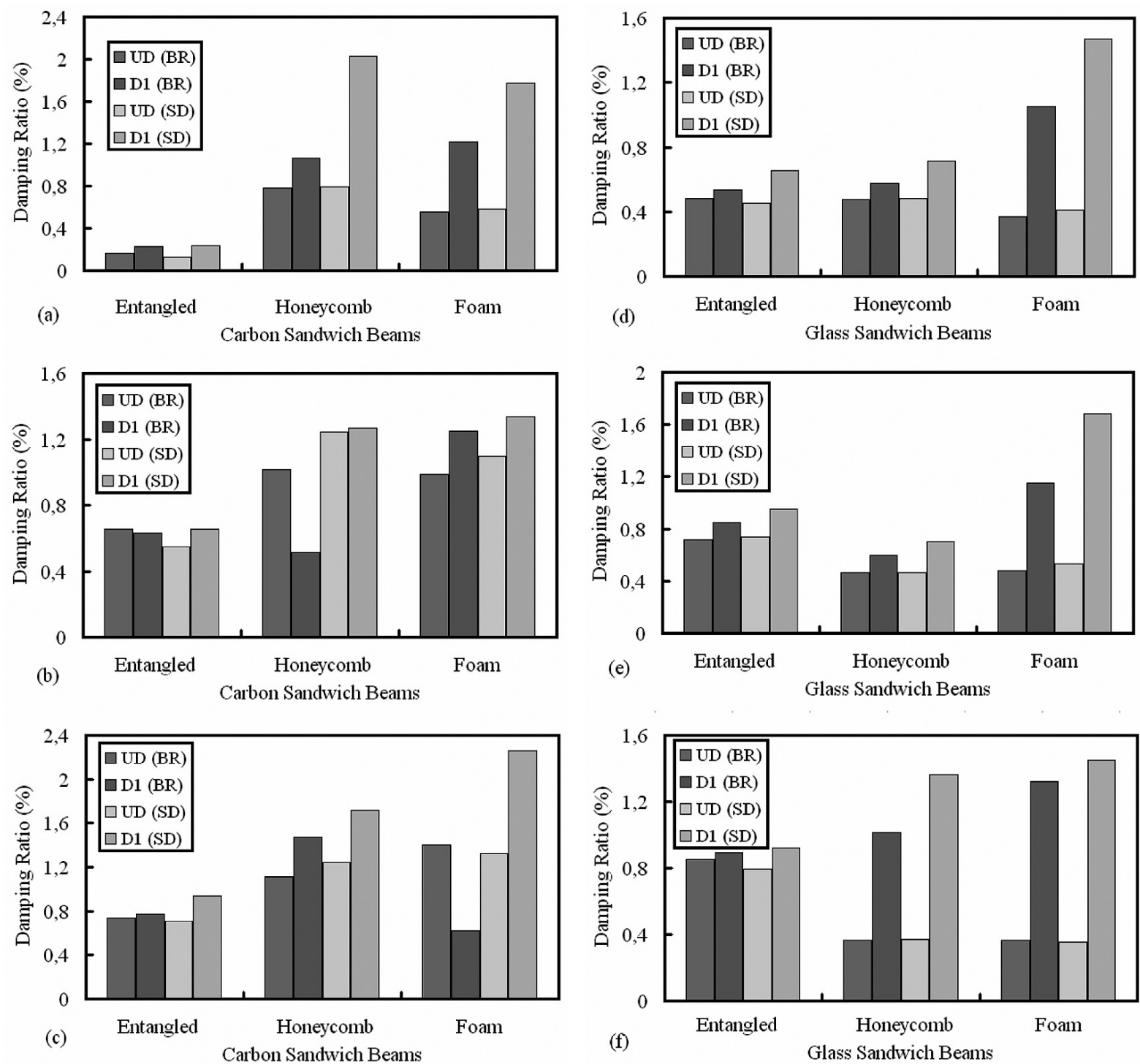

Fig. 12. Variation of damping ratio with damage states (a) 1st bending mode, (b) 2nd bending mode and (c) 3rd bending mode for the carbon sandwich beams and (d) 1st bending mode, (e) 2 nd bending mode and (f) 3rd bending mode for the glass sandwich beams: UD is undamaged state, D1 is damaged at 2 impact points for both burst random (BR) and sine-dwell (SD) testing.

Tables 8 and 9 show that the shift in modal parameters is less in case of the entangled sandwich beams which signifies that they possess better impact toughness as compared to the standard sandwich beams with honeycomb and foam as core materials. It can also be noticed that the change in damping ratios is greater in case of sine dwell testing, because the damping ratio estimated by sine-dwell testing is always higher in case of the damaged state (D1) as compared to the burst random testing. Furthermore, the results in Tables 8 and 9 underline the fact that the damping change ratios are more prominent than the frequency change ratios. The maximum damping change ratio is $310 \%$ whereas the maximum frequency change ratio is $25 \%$. It can be concluded from the above results that damping seems more sensitive to damage than the natural frequency variations in case of honeycomb sandwich beams. So it is reasonable to assume that damping may be used instead of natural frequency as a damage indicator tool for structural health monitoring purposes. However, the fact that damping is a parameter that is relatively difficult to estimate as compared to natural frequency has to be taken into account. 


\section{Conclusion}

The aim of the article is to evaluate the resistance against impact of entangled sandwich beams by the pole shift which signifies loss of rigidity (decrease in natural frequency) and increase in friction in damaged zone (increase in damping ratio). A simple case of symmetrical impacts is studied and Low Velocity Impacts are done below the BVID limit in order to detect damage by vibration testing that is hardly visible on the surface. From the results it can be concluded that both carbon and glass fiber entangled sandwich beams show a better resistance to impact (based only on decrease in natural frequency) as compared to the honeycomb and foam sandwich beams, whereas all the beams have more or less the same level damage.

\section{Acknowledgments}

The authors gratefully thank research project student Hanno Niemann from TU Braunschweig for his technical support during the impact tests.

\section{Nomenclature}

$\begin{array}{ll}\mathrm{BR} & =\text { Burst random testing } \\ \mathrm{SD} & =\text { Sine-dwell testing } \\ \mathrm{UD} & =\text { undamaged state } \\ \mathrm{D} 1 & =\text { damaged state at } 2 \text { points } \\ \mathrm{FRF} & =\text { Frequency Response Function } \\ \mathrm{H}(\omega) & =\text { Frequency Response Function matrix } \\ \mathrm{j} & =\text { Imaginary axis in the complex plane } \\ & =\text { Complex conjugate } \\ \omega(k) & =\text { Modal damped frequency for kth mode }(\mathrm{rad} / \mathrm{s}) \\ p(k) & =\text { Pole location for the kth mode } \\ R(k) & =\text { Residue magnitude (FRF/s) } \\ \sigma(k) & =\text { Modal damping for kth mode } \\ \omega_{n} & =\text { Undamped natural frequency (rad/s) } \\ \omega_{d} & =\text { Damped natural frequency (rad/s) } \\ \mathrm{C} & =\text { Structural damping matrix (force/velocity) } \\ \mathrm{K} & =\text { Stiffness matrix (force/displacement) } \\ \mathrm{M} & =\text { Mass matrix } \\ \mathrm{f}_{k} & =\text { Resonance frequency (Hz) for the kth mode } \\ \zeta_{k} & =\text { Damping ratio (\%) for the kth mode }\end{array}$

\section{References}

[1] S.W. Doebling, C.R. Farrar and M.B. Prime, A summary review of vibration-based damage identification methods, Shock and Vibration Digest 30 (1998), 91-105.

[2] Y.J. Yan, L. Cheng, Z.Y. Wu and L.H. Yam, Development in vibration-based structural damage detection technique, Mechanical Systems and Signal Processing 21 (2007), 2198-2211.

[3] H. Sohn, C.R. Farrar, F.M. Hemez, D. Shunk, D.W. Stinemates and B.R. Nadler, A review of structural health monitoring literature: (1996-2001) Los Alamos National Laboratory Report LA-13976-MS

[4] E.P. Carden and P. Fanning, Vibration based condition monitoring: A review, Structural Health Monitoring 3(4) (2004), 355-377.

[5] H. Van der Auweraer, International research projects on structural damage detection, Damage Assessment of Structures Key Engineering Materials 204(2) (2001), 97-112.

[6] O.S. Salawu, Detection of structural damage through changes in frequency: a review, Engineering Structures 19(9) (1996), 718-723.

[7] L.M. Khoo, P.R. Mantena and P. Jadhav, Structural damage assessment using vibration modal analysis, Structural Health Monitoring 3(2) (2004), 177-194. 
[8] R.M. Gadelrab, The effect of delamination on the natural frequencies of a laminated composite beam, Journal of Sound and Vibration 197(3) (1996), 283-292.

[9] L.H. Yam and L. Cheng, Damage detection of composite structures using dynamic analysis, Key Engineering Materials 295-296 (2005), 33-39.

[10] H.Y. Kim and W. Hwang, Effect of debonding on natural frequencies and frequency response functions of honeycomb sandwich beams, Composite Structures 55 (2002), 51-62.

[11] A. Shahdin, J. Morlier and Y. Gourinat, Correlating low energy impact damage with changes in modal parameters: A preliminary study on composite beams, Structural Health Monitoring 8 (2009), 523-536.

[12] R.D. Adams, Damping in composites, Material Science Forum 119-121 (1993), 3-16.

[13] Z. Zhang and G. Hartwig, Relation of damping and fatigue damage of unidirectional fibre composites, International Journal of Fatigue 24 (2004), 713-738.

[14] R.F. Gibson, Modal vibration response measurements for characterization of composite materials and structures, Composites Science and Technology 60 (2000), 2769-2780.

[15] D.A. Saravanos and D.A. Hopkins, Effects of delaminations on the damped dynamic characteristics of composites, Journal of Sound and Vibration 192 (1995), 977-993.

[16] P.M. Schubel, J.J. Luo and I.M. Daniel, Impact and post impact behaviour of composite sandwich panels, Composites Part A 38 (2007), 1051-1057.

[17] S. Petit, C. Bouvet, A. Bergerot and J.J. Barrau, Impact and compression after impact experimental study of a composite laminate with a cork thermal shield, Composites Science and Technology 67 (2007), 3286-3299.

[18] E. Abi Abdallah, C. Bouvet, B. Broll and J.J. Barrau, Experimental analysis of damage creation and permanent indentation on highly oriented plates, Composites Science and Technology 69(7-8) (2009), 1238-1245.

[19] S. Abrate, Impact on composite structures. Cambridge University Press 1988.

[20] M.O.W. Richardson and M.J. Wisheart, Review of low-velocity impact properties of composite materials, Composites Part A 27 (1996), 1123-1131.

[21] J.P. Dear, H. Lee and S.A. Brown, Impact damage processes in composite sheet and sandwich honeycomb materials, International Journal of Impact Engineering 32 (2005), 130-154.

[22] U.K. Vaidya, S. Pillay, S. Bartus, C. Ulven, D.T. Grow and B. Mathew, Impact and post-impact vibration response of protective metal foam composite sandwich plates, Materials Science and Engineering A 428 (2006), 59-66.

[23] U.K. Vaidya, S. Pillay, C. Ulven, G.M. Janowski and M.V. Hosur, Low velocity impact and vibration response of multi functional sandwich plates, 17th American Society for Composites Technical Conference, Indiana, 2002.

[24] M.V. Hosur, M. Abdullah and S. Jeelani, Manufacturing and low-velocity impact characterization of foam filled 3-D integrated core sandwich composites with hybrid face sheets, Composite Structures 69(2) (2005), 167-181.

[25] U.K. Vaidya, M.V. Hosur, D. Earl and S. Jeelani, Impact response of integrated hollow core sandwich composite panels, Composites Part A 31(8) (2000), 761-772.

[26] L.S. Sutherland and C. Guedes Soares, Impact characterisation of low fiber-volume glass reinforced polyester circular laminated plates, International Journal of Impact Engineering 31(1) (2005), 1-23.

[27] L.S. Sutherland and C. Guedes Soares, Effect of laminate thickness and of matrix resin on the impact of low fiber-volume, woven roving E-glass composites, Composites Science and Technology 64(10-11) (2004), 1691-1700.

[28] M.R. Abdullah and W.J. Cantwell, The impact resistance of polyporopylene based fiber-metal laminates, Composites Science and Technology 66(11-12) (2006), 1682-1693.

[29] A. Shahdin, L. Mezeix, C. Bouvet, J. Morlier and Y. Gourinat, Fabrication and mechanical testing of a new sandwich structure with carbon fiber network core, Journal of Sandwich Structures and Materials (2009), doi:10.1177/1099636209106070.

[30] A. Shahdin, L. Mezeix, C. Bouvet, J. Morlier and Y. Gourinat, Fabrication and mechanical testing of glass fiber entangled sandwich beams: A comparison with honeycomb and foam sandwich beams, Composite Structures 90 (2009), 404-412.

[31] A. Shahdin, L. Mezeix, C. Bouvet, J. Morlier and Y. Gourinat, Monitoring the effects of impact damages on modal parameters in carbon fiber entangled sandwich beams, Engineering Structures 31 (2009), 2833-2841.

[32] J. Dean, A.S. Fallah, P.M. Brown, L.A. Louca and T.W. Clyne, Energy absorption during projectile perforation of lightweight panels with metallic fibre cores. 8th International Conference on Sandwich Structures (ICSS 8), Porto, 2008.

[33] HexPly M21. Data Sheet, Hexcel Composites, F.R.

[34] HexWeb ${ }^{\mathrm{TM}}$. Honeycomb attributes and properties, Hexcel Composites, F.R.

[35] J.L. Wojtowicki and L. Jaouen, New approach for the measurements of damping properties of materials using oberst beam, Review of Scientific Instruments 75(8) (2004), 2569-2574.

[36] G. Gloth and M. Sinapius, Influence and characterisation of weak non-linearities in swept-sine modal testing, Aerospace Science and Technology 8 (2004), 111-120.

[37] The Fundamentals of Modal Testing, Application Note 243 - 3, Agilent Technology.

[38] A. Shahdin, J. Morlier and Y. Gourinat, Damage monitoring in sandwich beams by modal parameter shifts: A comparative study of burst random and sine dwell vibration testing, Journal of Sound and Vibration 329 (2010), 566-584.

[39] B. Peeters, H.V. Auweraer, P. Guillaume and J. Leuridan, The PolyMAX frequency-domain method: a new standard for modal parameter estimation, Shock and Vibrations 11 (2004), 395-409.

[40] B.J. Schwarz and M.H. Richardson, Experimental Modal Analysis, CSI Reliability week Orlando FL (1999).

[41] J. Morlier, B. Chermain and Y. Gourinat, Original statistical approach for the reliability in modal parameters estimation, IMAC XXVII (2009). 

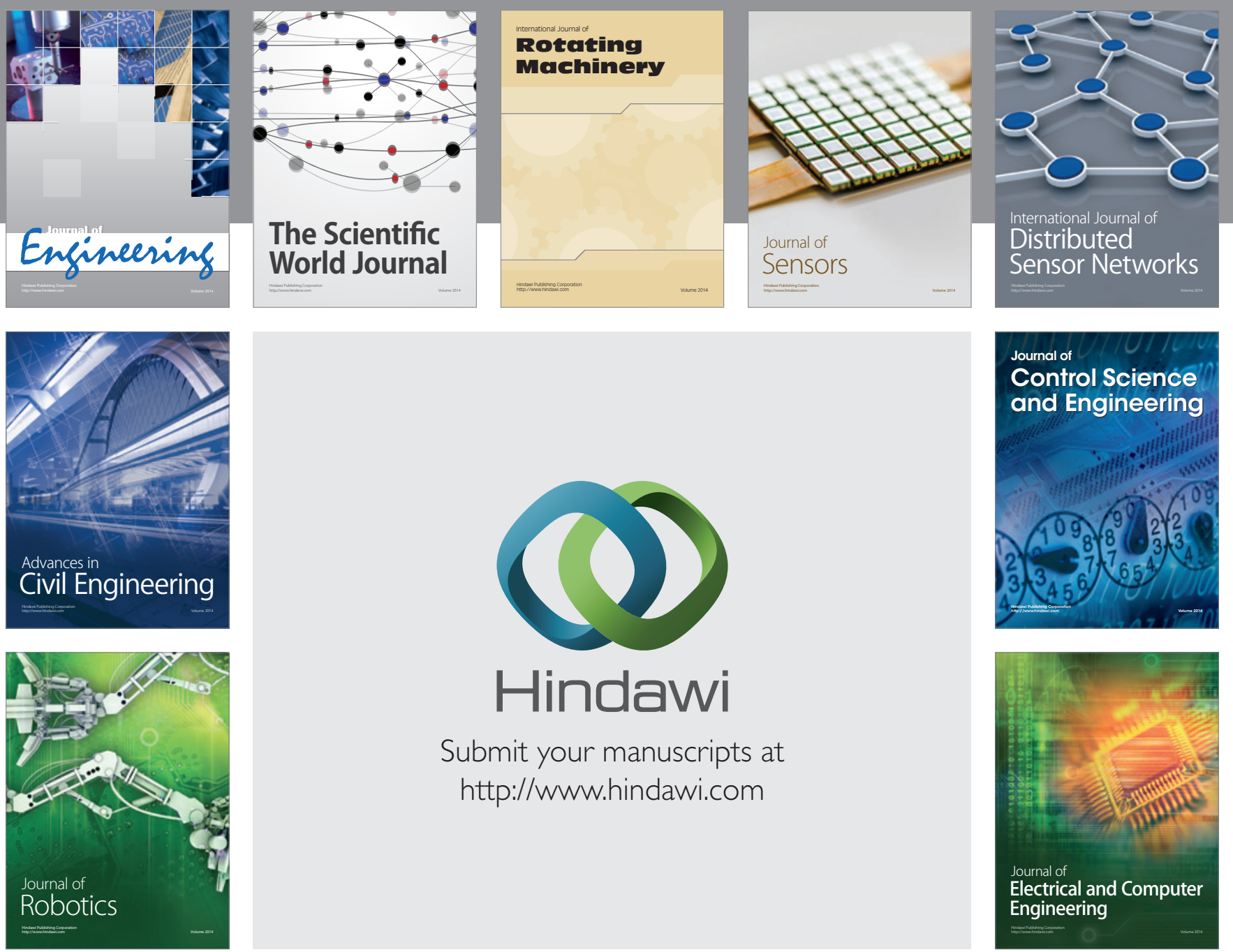

Submit your manuscripts at

http://www.hindawi.com
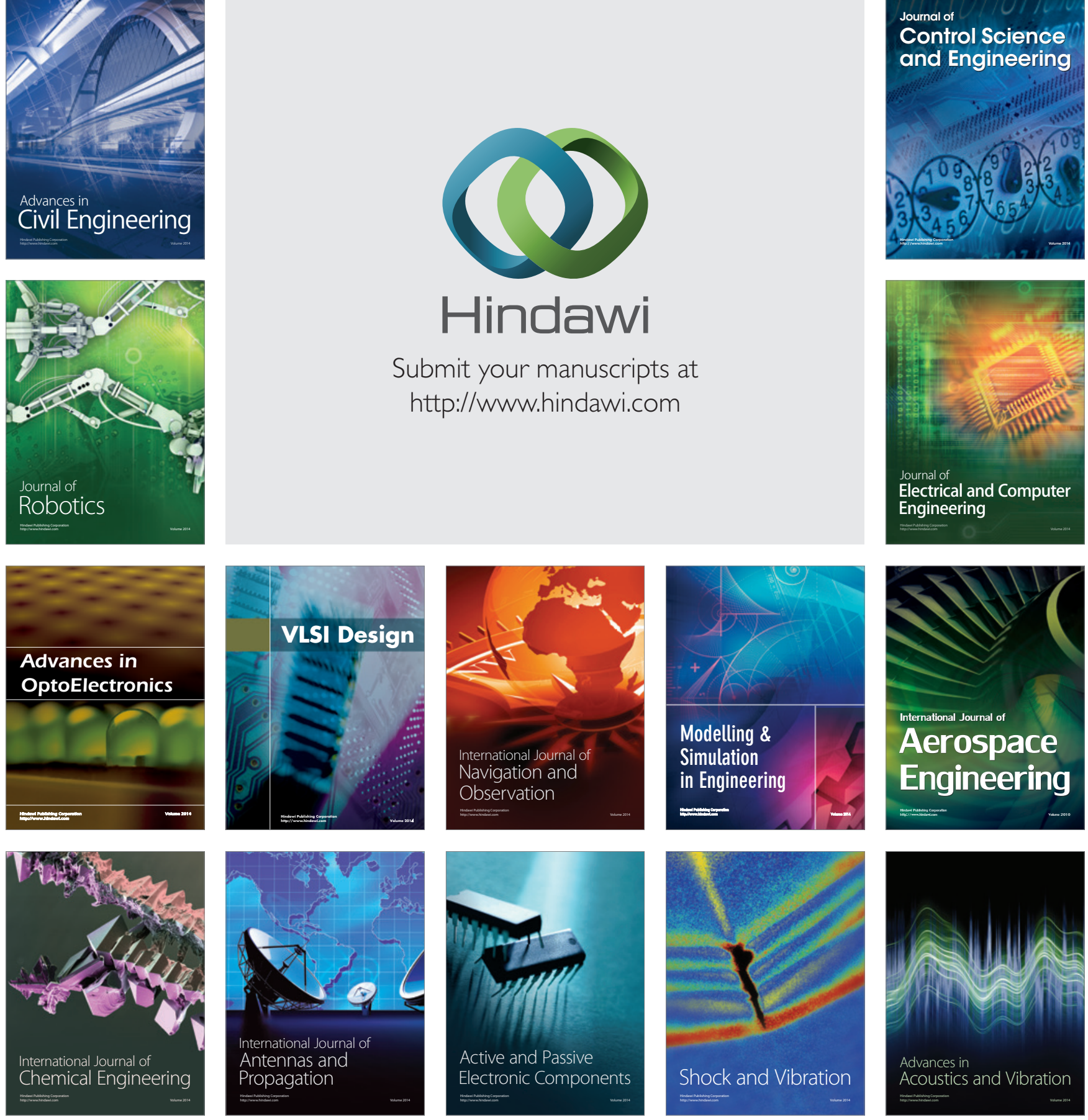